\title{
Resource Provider Effective Date Range
}

National Cancer Institute

\section{Source}

National Cancer Institute. Resource Provider Effective Date Range. NCI Thesaurus. Code C94068.

The date and time span for when the resource provider is active. 